\title{
Properties and Performance of High-Purity Thermal Barrier Coatings
}

\author{
L. Xie, M.R. Dorfman, A. Cipitria, S. Paul, I.O. Golosnoy, and T.W. Clyne
}

(Submitted March 10, 2007; in revised form July 5, 2007)

\begin{abstract}
It has been found that reducing the level of impurity oxides (particularly $\mathrm{SiO}_{2}$ and $\mathrm{Al}_{2} \mathrm{O}_{3}$ ) in $7 \mathrm{YSZ}$, from about $0.2 \mathrm{wt} \%$ to below $0.1 \mathrm{wt} \%$ raises the sintering resistance and the phase stability of plasma-sprayed coatings. The implications for the usage of these coatings at elevated temperatures are examined. It is concluded that using relatively high-purity powder of this type is likely to confer substantial benefits in terms of the thermomechanical stability of the coatings under service conditions.
\end{abstract}

Keywords impurities, phase stability, plasma-sprayed thermal barrier coatings, sintering, thermal conductivity, thermal cyclic life, young's modulus

\section{Introduction}

Thermal-barrier coatings (TBCs) provide thermal protection for metallic components in hot sections of gas turbine power generation plants and aero engines (Ref 16). Current use of TBCs typically allows an increase of $\sim 100-150{ }^{\circ} \mathrm{C}$ in turbine entry temperature (Ref 7). The continuing drive to raise this temperature means that there is a strong incentive to develop TBCs that remain stable at higher temperatures.

Currently, $\sim 7-8$ wt. \% yttrium $\left(\mathrm{Y}_{2} \mathrm{O}_{3}\right)$ stabilized zirconia $\left(\mathrm{ZrO}_{2}\right)(7 \mathrm{YSZ})$ is the material of choice, due to its low thermal conductivity and high thermal expansion coefficient. However, when 7YSZ TBCs are exposed to temperatures higher than $1200{ }^{\circ} \mathrm{C}$, sintering and phase transformation of 7YSZ tend to become significant and cause degradation or even spallation of TBCs (Ref 7-9).

In the past decade, extensive research on advanced TBCs has resulted in the discovery of dozens of new TBC materials that have either lower thermal conductivity or improved phase stability or both (Ref 10). For example, multi-doped zirconia (Ref 11) and gadolinium zirconate

This article is an invited paper selected from presentations at the 2007 International Thermal Spray Conference and has been expanded from the original presentation. It is simultaneously published in Global Coating Solutions, Proceedings of the 2007 International Thermal Spray Conference, Beijing, China, May 14-16, 2007, Basil R. Marple, Margaret M. Hyland, Yuk-Chiu Lau, Chang-Jiu Li, Rogerio S. Lima, and Ghislain Montavon, Ed., ASM International, Materials Park, OH, 2007.

L. Xie and M.R. Dorfman, Sulzer Metco (US) Inc, Westbury, New York; and A. Cipitria, S. Paul, I.O. Golosnoy, and T.W. Clyne, Department of Materials Science \& Metallurgy, University of Cambridge, Cambridge, UK. Contact e-mail: ac472@ cam.ac.uk.
$\left(\mathrm{Gd}_{2} \mathrm{Zr}_{2} \mathrm{O}_{7}\right)$ (Ref 12) have a thermal conductivity of less than half that of 7YSZ. In addition, these coatings exhibit significantly enhanced sintering resistance.

A factor thought to affect the sintering behavior of TBCs is the content of impurity oxides, such as silica $\left(\mathrm{SiO}_{2}\right)$ and alumina $\left(\mathrm{Al}_{2} \mathrm{O}_{3}\right)$. Higher levels tend to result in more rapid sintering (Ref 13). However, the effect of purity on TBC properties has not been fully investigated or understood. In the present article, mechanical and thermal properties of a high-purity 7YSZ plasma sprayed TBC are evaluated and compared to those of TBCs of lower purity. In addition, the potential of novel high purity TBCs is discussed.

\section{Experimental}

TBCs were produced using three 7YSZ powders of different purity, with identical processing conditions (Table 1). Except for thermal cycling samples, all coatings were deposited on mild steel substrates, precoated with $\sim 50 \mu \mathrm{m} \mathrm{Al}$ to facilitate the debonding of the TBC from the substrate with hydrochloric acid. Coating ZY-1 had a high concentration of $\mathrm{SiO}_{2}$; coating $\mathrm{ZY}-2$, a high concentration of $\mathrm{Al}_{2} \mathrm{O}_{3}$; coating $\mathrm{ZY}-3$, a very low concentration of all impurity oxides and coating $\mathrm{ZY}-4$, an average impurity level, intermediate between the very pure ZY-3 and the coatings with high $\mathrm{SiO}_{2}$ and $\mathrm{Al}_{2} \mathrm{O}_{3}$ content (Table 2).

Dilatometry (DIL 402C dilatometer, Netzsch, Selb, Germany) was carried out on freestanding coatings, with the specimens held at $1400{ }^{\circ} \mathrm{C}$ for $20 \mathrm{~h}$. The phase constitution after heat treatment at $1400{ }^{\circ} \mathrm{C}$ was evaluated using x-ray diffraction (XRD). Changes in thermal conductivity (in the through-thickness direction) after heat treatment were measured using a Transient Plane Source (TPS) technique (Ref 14) (Hot Disk TPS 2500, Uppsala, Sweden). Young's moduli of as-sprayed and heat treated coatings (in the in-plane direction) were measured using a purpose-built four-point bending rig (Ref 15).

TBCs deposited over a bond coat (air plasma sprayed CoNiCrAlY, Amdry 995C, Sulzer Metco, Westbury, 
Table 1 Plasma-spraying conditions (Sulzer Metco 9MB plasma system, Sulzer Metco, Westbury, New York)

\begin{tabular}{lcccccc}
\hline $\begin{array}{l}\mathbf{N}_{\mathbf{2}}, \\
\mathbf{L} / \mathbf{m i n}\end{array}$ & $\begin{array}{c}\mathbf{H}_{\mathbf{2}}, \\
\mathbf{L} / \mathbf{m i n}\end{array}$ & $\begin{array}{c}\mathbf{C G F}, \mathbf{N}_{\mathbf{2}}, \\
\mathbf{L} / \mathbf{m i n}\end{array}$ & $\begin{array}{c}\mathbf{I}, \\
\mathbf{A}\end{array}$ & $\begin{array}{c}\mathbf{P}, \\
\mathbf{K W}\end{array}$ & $\begin{array}{c}\text { Feed rate, } \\
\mathbf{g} / \mathbf{m i n}\end{array}$ & $\begin{array}{c}\mathbf{S D} \text {, } \\
\mathbf{m m}\end{array}$ \\
\hline 35.4 & 8.0 & 5.2 & 500 & 39.3 & 46 & 114
\end{tabular}

$\mathrm{N}_{2}$ - primary plasma gas, $\mathrm{H}_{2}$ - secondary plasma gas, CGF-carrier gas $\left(\mathrm{N}_{2}\right)$ flow, $\mathrm{I}$-current, $\mathrm{P}$-input power calculated using voltage measured at the power supply, SD-standoff distance

Table 2 Compositions of the coatings

\begin{tabular}{lcccrcr}
\hline Sample ID & $\mathbf{Z r O}_{2}$ & $\mathbf{Y}_{\mathbf{2}} \mathbf{O}_{\mathbf{3}}$ & $\mathbf{A l}_{\mathbf{2}} \mathbf{O}_{\mathbf{3}}$ & $\mathbf{S i O}_{\mathbf{2}}$ & $\mathbf{T h}$ & \multicolumn{1}{c}{$\mathbf{U}$} \\
\hline ZY-1 & Rem. & 7.78 & 0.09 & 0.18 & 0.01 & 0.018 \\
ZY-2 & Rem. & 7.79 & 0.2 & 0.09 & 0.012 & 0.016 \\
ZY-3 & Rem. & 7.57 & $<0.02$ & $<0.02$ & $<0.002$ & $<0.002$ \\
ZY-4 & Rem. & 7.41 & 0.07 & 0.02 & $<0.002$ & $<0.002$ \\
\hline
\end{tabular}

New York) on a Ni-base superalloy substrate (Hastelloy $\mathrm{X})$ were thermally cycled in air using a $\mathrm{CM}^{\mathrm{TM}}$ rapid temperature furnace (CM Inc. Bloomfield, N.J.). The thermal cycle consisted of a 10-min heat-up from room temperature to $1121{ }^{\circ} \mathrm{C}\left(2050{ }^{\circ} \mathrm{F}\right)$, a 40 -min hold at $1121^{\circ} \mathrm{C}\left(2050^{\circ} \mathrm{F}\right)$ and a 10 -min forced air quench. A sample was considered to have failed when the TBC spalled area reached $50 \%$ of the total area.

\section{Results}

\subsection{Sintering Shrinkage}

Slab samples $(1 \mathrm{~mm} \times 2 \mathrm{~mm} \times 2 \mathrm{~mm})$ were cut from free-standing coatings and loaded into a heating tube, with the through-thickness direction aligned with the transducer (so that the shrinkage normal to the coating/substrate interface was being monitored). After heating to $1400{ }^{\circ} \mathrm{C}$, the change in length with time was recorded. The linear shrinkage after $20 \mathrm{~h}$ at $1400{ }^{\circ} \mathrm{C}$ was $1.6 \%$ for $\mathrm{ZY}-1$ (high $\mathrm{SiO}_{2}$ content) and $1.4 \%$ for $\mathrm{ZY}-2$ (high $\mathrm{Al}_{2} \mathrm{O}_{3}$ content), while that for ZY-3 (high purity) was less than $0.4 \%$ (see Fig. 1).

\subsection{Thermal Conductivity}

Before heat treatment, the thermal conductivity of all three coatings was measured to be $\sim 0.9 \mathrm{~W} / \mathrm{mK}$. This is broadly in line with previously published data, obtained using the laser flash technique (Ref 12). It is also consistent with the conductivity being sensitive to microstructural features, particularly the pore architecture, but not to impurity content. After $1 \mathrm{~h}$ at $1400{ }^{\circ} \mathrm{C}$ (Fig. 2), the conductivity of all samples increased by more than $50 \%$. This is attributed (Ref 15$)$ to rapid sintering of microcracks and fine scale porosity $(<100 \mathrm{~nm})$. Figure 2 also shows that the conductivity continues to increase with increasing time at high temperature, particularly for the samples with higher impurity levels. This behavior clearly mirrors the sintering

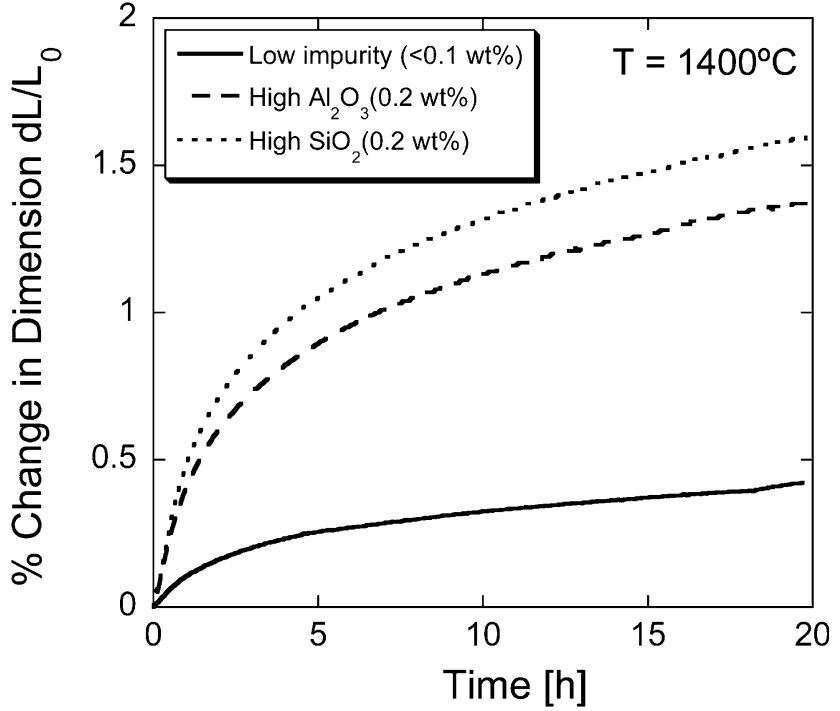

Fig. 1 Through-thickness shrinkage behavior at $1400{ }^{\circ} \mathrm{C}$

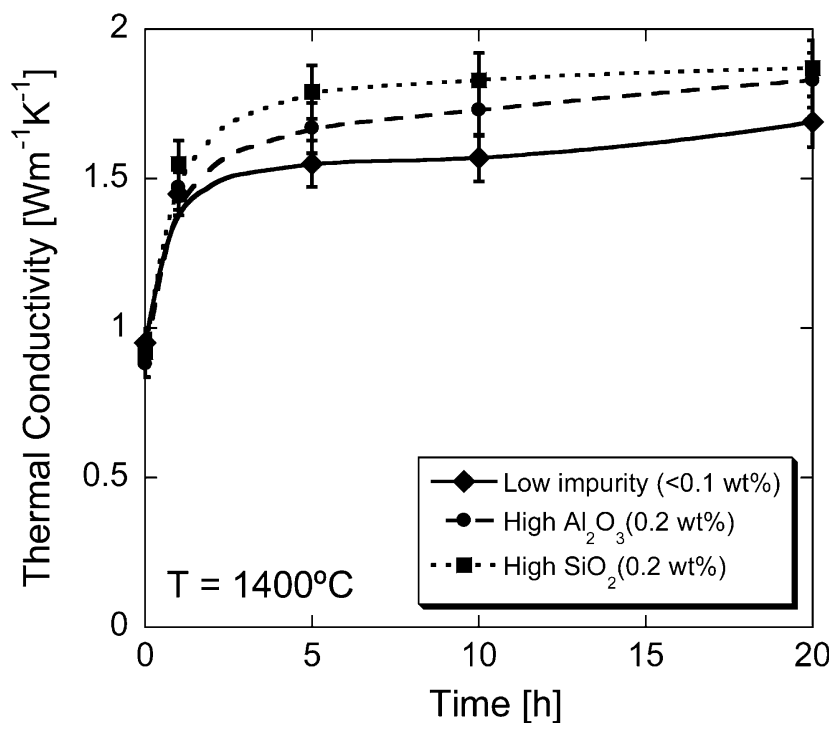

Fig. 2 Change of thermal conductivity with time at $1400{ }^{\circ} \mathrm{C}$

behavior and the increases in conductivity can be attributed primarily to improved inter-splat bonding as a result of sintering phenomena.

\subsection{Phase Stability}

Prior to heat treatment, only the nontransformable tetragonal phase $\left(\mathrm{t}^{\prime}\right)$ was detected in all three coatings. After $20 \mathrm{~h}$ at $1400{ }^{\circ} \mathrm{C}$ (Fig. 3a), less than $1 \%$ of monoclinic zirconia was detected for all three coatings. However, significant levels of cubic zirconia were found, estimated (using the intensity of (111) peaks) as 42, 45, and $27 \%$, for ZY-1, ZY-2, and ZY-3, respectively. With increasing heat treatment time (Fig. 3b), more $\mathrm{t}^{\prime}$ phase zirconia transforms to cubic and then to monoclinic phase,

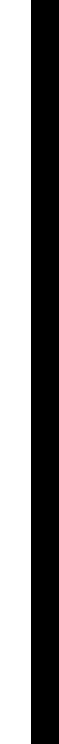



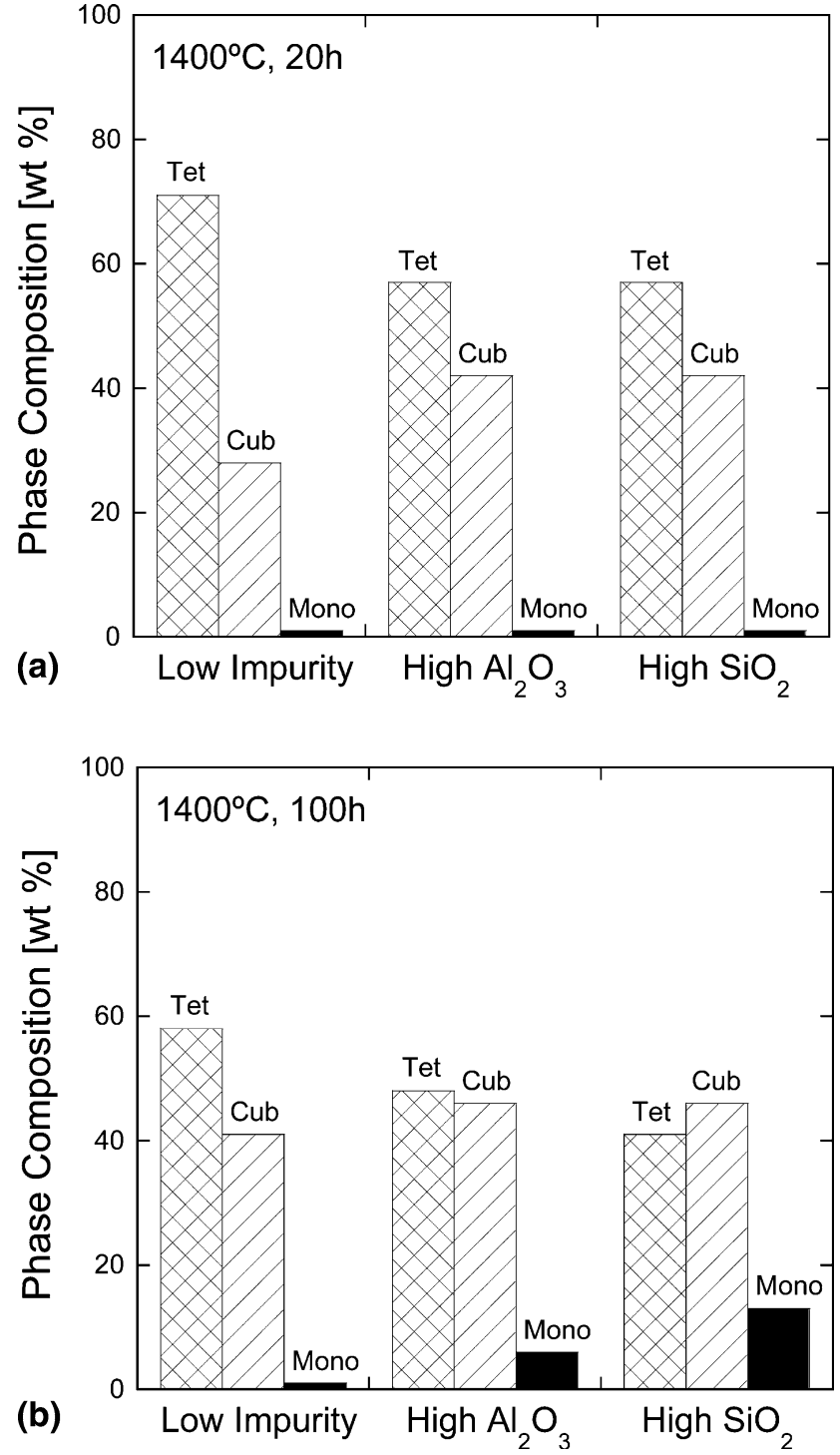

Fig. 3 Phase constitution for the three compositions after (a) $20 \mathrm{~h}$ and (b) $100 \mathrm{~h}$ at $1400{ }^{\circ} \mathrm{C}$

due to partitioning of yttrium at high temperatures. Relative to $\mathrm{ZY}-1$ (high $\mathrm{SiO}_{2}$ content) and $\mathrm{ZY}-2$ (high $\mathrm{Al}_{2} \mathrm{O}_{3}$ content), it can be seen (Fig. 3b) that, after $100 \mathrm{~h}$ at $1400{ }^{\circ} \mathrm{C}$, the high purity coating ZY-3 retained more tetragonal phase $(56 \%)$ and formed less than $1 \%$ of monoclinic phase, while the monoclinic phase content for ZY-1 and ZY-2 was 16 and 7\%, respectively.

\subsection{Young's Modulus}

All three coatings had an in-plane Young's modulus of about $20 \mathrm{GPa}$ in the as-sprayed state. Changes during heat treatment (Fig. 4) reflect the sintering and conductivity behavior, in that a rapid increase occurred during the first hour, followed by further increases at a slower rate. Also, the increases were greater for the higher-impurity content samples.

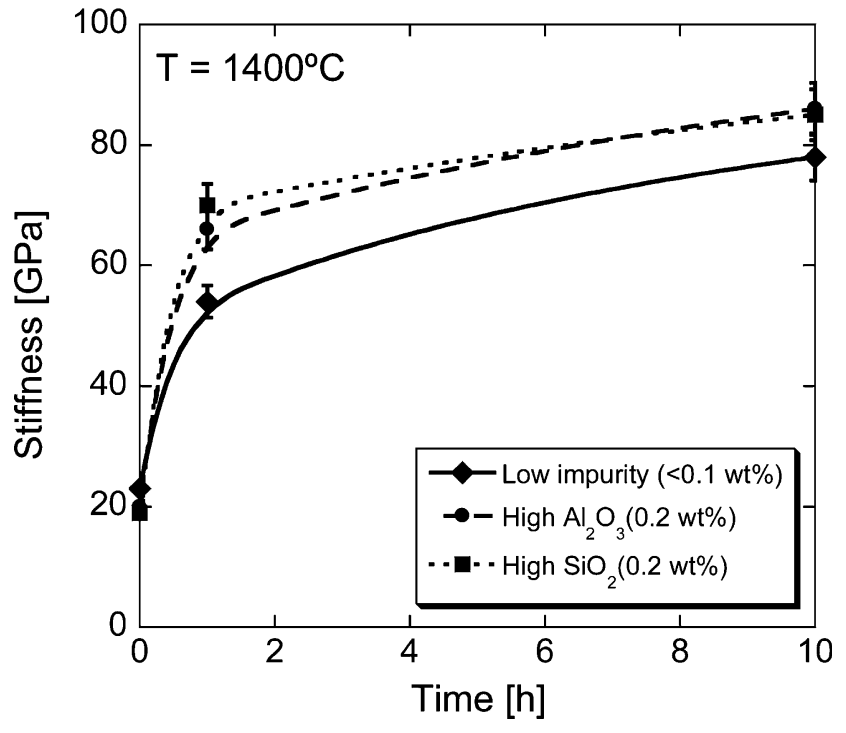

Fig. 4 Measured in plane Young's modulus data after heat treatment at $1400{ }^{\circ} \mathrm{C}$

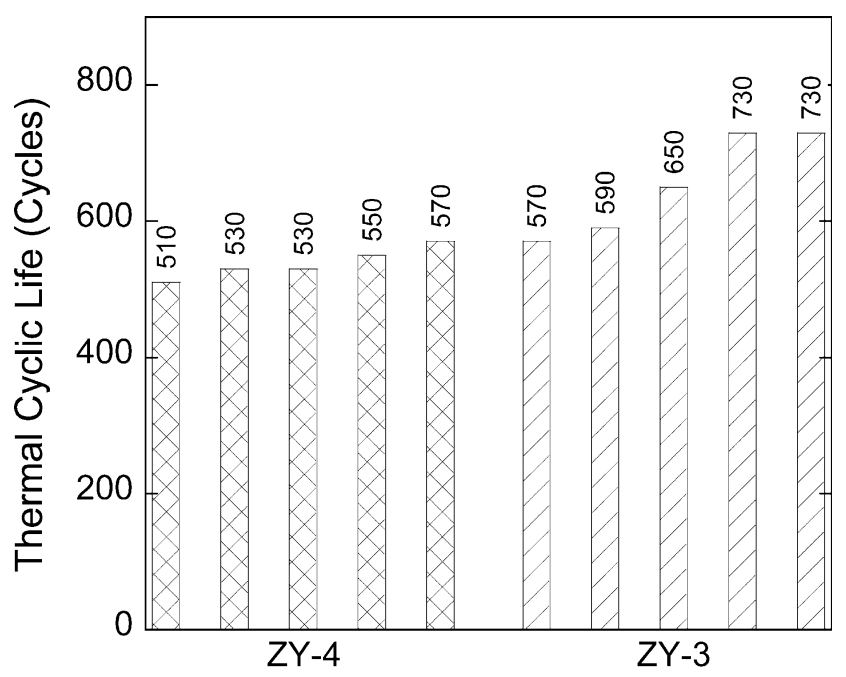

Fig. 5 Thermal cyclic life of ZY-3 and ZY-4

\subsection{Thermal Cyclic Life}

An initial comparison was made between ZY-3 (high purity) and ZY-4, which has purity higher than ZY-1 and ZY-2, but lower than ZY-3 (see Table 2). As shown in Fig. 5, the first failure of ZY-3 occurred at 570 cycles and the last at 730 cycles, while ZY-4 samples failed between 510 and 570 cycles.

\section{Discussion}

It has been previously reported (Ref 13) that relatively high concentrations of impurity oxides, especially $\mathrm{SiO}_{2}$ and $\mathrm{Al}_{2} \mathrm{O}_{3}$, can promote sintering in 7YSZ coatings. 
Further information about this effect is provided by the current work. The effect is certainly associated with the effect of impurities on phase constitution and/or diffusivities. Impurity oxides have been observed to segregate at fracture surfaces of 7YSZ TBCs (Ref 16). Such segregation probably occurs at grain boundaries and perhaps more strongly at inter-splat boundaries. When the concentrations of such impurities reach relatively high levels, there is a tendency to form vitreous phases with low glass transition temperatures, or crystalline phases with low melting points (Ref 17). It is thus possible that liquid phase sintering could occur, but even if there is insufficient vitreous material locally for viscous flow, the diffusion rates in such phases will tend to be high and solid phase sintering will thus be accelerated.

Sintering of TBCs leads to the reduction of void content, improved inter-splat bonding and healing of throughthickness microcracks. Fine inter-splat porosity and cracks, especially interfaces and cracks lying normal to the heat-flow direction, reduce the thermal conductivity. In addition, these defects contribute to the compliance and strain tolerance needed to accommodate the misfit strains generated during thermal cycling under service conditions. The stresses generated in the coating during such cycling become larger as the in-plane Young's modulus increases (Ref 8). Coatings exhibiting faster sintering, due to higher concentrations of impurity oxides, show more pronounced increases in thermal conductivity and Young's modulus. These effects thus both reduce the thermal protection provided by the coating and also make it more likely to undergo spallation.

The improved durability of ZY-3 relative to ZY-4 can be explained on this basis. The reduced sintering rate of the high purity coating results in less stiffening and a lower level of residual stress (due to the sintering shrinkage and to differential thermal contraction during thermal cycling). This, in turn, lowers the strain energy stored in the coating and thus diminishes the driving force for coating spallation (Ref 9). Furthermore, under service conditions (with through-thickness thermal gradients) a lower increase in thermal conductivity, due to a slower sintering rate, will ensure that the bond coat remains cooler and thus slow its oxidation and the growth of the thermally grown oxide (TGO). Since bond coat oxidation and TGO growth is often thought to be a major contributory factor for TBC spallation (Ref 18), the beneficial effect of higher purity on coating durability is expected to be more significant under thermal gradient conditions than during an isothermal cycling test (Fig. 5).

As mentioned above, higher purity leads to reduced sintering, by inhibiting the formation of undesirable phases and the stimulation of faster lattice diffusion. The work presented here has confirmed that this effect is significant for the temperature range of prime interest and has also given indications about the purity levels that are required in order to give substantial benefits (< $0.1 \mathrm{wt} \%$ ).

It may be noted that extensive efforts have also been focused on reducing the mobility of dopants, in order to improve the sintering resistance and to lower the thermal conductivity of TBCs (Ref 11, 12). Since these two mechanisms are different from the purity effect studied here, a combination of high purity and controlled dopant level might be expected to result in further improvements in sintering resistance.

\section{Summary and Conclusion}

Mechanical and thermal properties of 7YSZ TBCs have been measured for a range of purity levels. It has been found that a reduction in impurity oxide levels (notably $\mathrm{SiO}_{2}$ and $\mathrm{Al}_{2} \mathrm{O}_{3}$ ) can significantly enhance the sintering resistance and phase stability. This improved sintering resistance confers greater thermal stability and a reduced tendency for increases in thermal conductivity and stiffness to occur under service conditions.

\section{Acknowledgments}

The authors would like to thank Israel Aguilar for technical support. They are also grateful to EPSRC, The Basque Government and the Gates Foundation for financial support.

\section{References}

1. D. Parker, Application of Thermal Barrier Coatings, Mater Des, 1993, 14, p 345

2. N. Padture, M. Gell, and E. Jordan, Thermal Barrier Coatings for Gas-Turbine, Science, 2002, 296, p 280

3. R. Miller, Thermal Barrier Coatings for Advanced Gas Turbine and Diesel Engines, J. Therm. Spray Technol., 1997, 6, p 35

4. S. Miller, Current Status of Thermal Barrier Coatings-An Overview, Mater. World, 1996, 4, p 446

5. S. Meier and D. Gupta, Thermal Barrier Coating Life Prediction Model Development, J. Eng. Gas Turbines Power, 1994, 116, p 250

6. S. Bose and J. DeMasi-Marcin, Thermal Barrier Coating Experience in Gas Turbine Engines at Pratt and Whitney, J. Therm. Spray Technol., 1997, 6, p 99

7. R. Jones, Thermal Barrier Coatings, Metallurgical and Ceramic Coatings, K.H. Stern, Ed., Chapman \& Hall, 1996, p 194

8. J.A. Thompson and T.W. Clyne, The Effect of Heat Treatment on the Stiffness of Zirconia Top Coats in Plasma-Sprayed TBCs, Acta Mater., 2001, 49, p 1565

9. T.W. Clyne and S.C. Gill, Residual Stresses in Thermally Sprayed Coatings and their Effect on Interfacial Adhesion-A Review of Recent Work, J. Therm. Spray Technol., 1996, 5, p 1

10. C. Levi, Emerging Materials and Processes for Thermal Barrier Systems, Curr. Opin. Solid State Mater. Sci., 2004, 8, p 77-91

11. M. Michael, Thermal Barrier Coating Systems and Materials, US Patent No. 6,284,323, 2001

12. D. Zhu and R. Miller, Development of Advanced Low Conductivity Thermal Barrier Coatings, Int, J. Appl. Ceram. Technol., 2004, 1(1), p 86

13. R. Vaßen, N. Czech, W. Malléner, W. Stamm, and D. Stöver, Influence of Impurity Content and Porosity of Plasma-Sprayed Yttria-Stabilized Zirconia Layers on the Sintering Behaviour, Surf. Coat. Technol., 2001, 141, p 135-140

14. S. Gustafsson, Transient Plane Source Techniques for Thermal Conductivity and Thermal Diffusivity Measurements of Solid Materials, Rev. Sci. Instrum., 1990, 62(3), p 797-804

15. S. Paul, I.O. Golosnoy, A. Cipitria, T.W. Clyne, L. Xie, and M. Dorfman, The Effects of Heat Treatment of Pore Architecture and Associated Property Changes in Plasma Sprayed TBC's, 
ITSC 2007 Proceedings, Beijing, China, May 14-17, 2007, p. 411,416

16. G. Ingo and G. Padeletti, Segregation Aspects at the Fracture Surfaces of $8 \mathrm{wt} \%$ Yttria-Zirconia Thermal Barrier Coatings, Surf. Interface Anal., 2004, 21(6-7), p 450-454
17. J. Rigney and R. Darolia, Thermally-Stabilized Thermal Barrier Coating, US Patent No. 6544665

18. A. Evans, D. Mumm, J. Hutchinson, G. Meier, and F. Pettit, Mechanisms Controlling the Durability of Thermal Barrier Coatings, Prog. Mater. Sci., 2001, 46, p 505 